\title{
Novel Test Bench for Inhaler Characterization Including Real-Time Determination of Output, Output Rate, and Liquid Water Content of Delivered Aerosols
}

\author{
Felix C. Wiegandt, MSc, ${ }^{1, *}$ Ulrich P. Froriep, Dr.rer.nat., ${ }^{1}$ Theodor Doll, Prof.Dr.-Ing.,, ${ }^{1,2}$ \\ Andreas Dietzel, Prof.Dr.rer.nat., ${ }^{3}$ and Gerhard Pohlmann, Dr.rer.nat. ${ }^{1, *}$
}

\begin{abstract}
Background: Developing new (triggered) or improving existing inhaler systems for (preterm) neonates and adults requires test benches for the determination of aerosol output and aerosol output rate. Furthermore, realtime measurement of aerosol output and output rate is advantageous with respect to both development costs and development time, especially when using liquid or humidified dry aerosols. The current standard test procedures following ISO 27427, however, are time-consuming. Moreover, these procedures are not applicable to inhalers for preterm neonates, due to their high breathing frequency, low tidal volume, and the dead space in commercially available test benches. We are describing a novel test bench approach combining gravimetric and optical detection to facilitate real-time measurement of aerosol output, aerosol output rate, and aerosol liquid water content in inhalation systems for (preterm) neonates and adults.

Methods: We integrated a laser-based optical measurement unit into test benches for inhalers for adults and preterm neonates, based on ISO 27427. Breathing was simulated by a sine pump for adults and by a test lung for preterm neonates on continuous positive airway pressure respiratory support. Dry or humidified aerosol was released by a continuous powder aerosolizer system. Simultaneous particle measurement by gravimetry (filter) and light extinction (laser system) was performed using the novel test benches.

Results: We developed test benches for inhalers for (preterm) neonates and adults in accordance with ISO 27427 , combining optical and gravimetric particle detection. Optical and gravimetric measurements conducted with these test benches were highly correlated, thus enabling real-time measurement of aerosol output and output rate. In addition, our test benches are suitable to determine the aerosol water content in situ directly at the patient interface. Conclusion: This novel test bench allows characterization of inhalation devices in real time and therefore will accelerate optimization and development cycles. Conformity with ISO 27427 allows its use in various applications.
\end{abstract}

Keywords: adult, inhaler characterization, ISO 27427, (preterm) neonate, real-time measurement, test bench

\section{Introduction}

T HE DEVELOPMENT AND TESTING of new inhalers or improvement of existing systems requires test benches to measure, among others, aerosol output and aerosol output rate $^{(1-8)}$ Furthermore, real-time measurement of aerosol output and aerosol output rate would be advantageous with respect to both development costs and time, especially when using liquid or humidified aerosols.

The standard procedure to measure the aerosol output and aerosol output rate of nebulizers is described in ISO 27427:2013(E), annex C. ${ }^{(9)}$ For testing of nebulizers, this standard recommends the aerosolization of sodium fluoride in a known concentration and sampling of the aerosol on a

\footnotetext{
${ }^{1}$ Fraunhofer Institute for Toxicology and Experimental Medicine ITEM, Hannover, Germany.

${ }^{2}$ Hannover Medical School, Hannover, Germany.

${ }^{3}$ Institute of Microtechnology, Technische Universität Braunschweig, Braunschweig, Germany.

*Member of ISAM.
}

(C) Felix C. Wiegandt, et al., 2020. Published by Mary Ann Liebert, Inc. This Open Access article is distributed under the terms of the Creative Commons License (http://creativecommons.org/licenses/by/4.0), which permits unrestricted use, distribution, and reproduction in any medium, provided the original work is properly credited. 
filter using a sine pump connected in series. According to annex $\mathrm{C}$, the sine pump shall simulate the respiratory flow of an adult with a tidal volume of $500 \mathrm{~mL}$, an inhalationexhalation ratio of $1: 1$, and a breathing frequency of 15 breaths/min. A filter is to be installed between the nebulizer and sine pump, collecting aerosol, which is chemically analyzed to determine the aerosol output and aerosol output rate. The device dead space between patient interface (e.g., a mouthpiece for adults or a nasal prong for preterm neonates) and the filter surface must not exceed $10 \%$ of the tidal volume. Otherwise, findings will be unacceptably reduced, as aerosol will fail to deposit on the filter. ${ }^{(9)}$

This standard procedure using adult breathing characteristics, as described above, takes significant time to determine the aerosol output and aerosol output rate due to elaborate chemical analysis or lengthy filter conditioning for gravimetric measurements. ${ }^{(9)}$

Furthermore, the aerosol liquid water content (ALWC) resulting, for example, from water absorption by particles or condensation of water on the surface of particles normally cannot be determined quantitatively without altering it, for example, by sampling and subsequent chemical analysis. The ALWC has an impact on optical properties (light extinction and light scattering), physical properties (particle size), and possibly chemical properties, making it an important parameter. Considering primarily dry particles, the ALWC mainly depends on hygroscopicity of the aerosol and relative ambient humidity. ${ }^{(10-14)}$ Due to the change in particle size as a function of the ALWC, it can have a significant influence on particle deposition in the respiratory tract. ${ }^{(15-18)}$

Often, a reduction of treatment time by maximizing inhaled concentrations is desirable. From a practical point of view, it is therefore desirable to minimize the number of test filters and to maximize filter loads. This is achieved by keeping the area of the collection filter as large as possible, so that the filter will not clog prematurely and will not require frequent replacements during testing.

This requirement, however, is in conflict with the stipulated dead volume smaller than $10 \%$ of the tidal volume. Therefore, standard procedures cannot be used for characterization especially of inhalers for preterm neonates, which require high breathing rates of up to 60 breaths $/ \mathrm{min}$, low tidal volumes of often less than $6 \mathrm{~mL} / \mathrm{kg}$, and, following ISO 27427 , dead spaces of less than $0.6 \mathrm{~mL} / \mathrm{kg}^{(19-21)}$

Pohlmann and Helwich ${ }^{(22)}$ have described a new method based on the standard process mentioned above to overcome this contradiction. This new method uses a closed flow circuit by which the dead space is reduced tremendously. Thus, a filter with high collection capacity can be used, which is advantageous for inhaler test benches for preterm neonates. However, even applying this new method, it still takes significant time to measure the aerosol output and aerosol output rate.

To overcome these time limitations, we see the necessity to develop a test bench that measures the aerosol output and aerosol output rate in real time using light extinction. Since the ALWC has a major impact on aerosol properties, a method to measure the ALWC must be included. It is known that under well-defined constant conditions, as during measurement of aerosol output and aerosol output rate, a particular inhaler delivers an aerosol whose particle size distribution does not change between measurements. Therefore, at sufficiently low concentrations, one can expect a linear correlation between light extinction and aerosol concentration, suitable for real-time measurement of aerosol concentration, and hence, assuming special framework conditions, of aerosol output and aerosol output rate. ${ }^{(23-25)}$

In the following, we describe two novel test benches for measuring aerosol output, output rate, and ALWC in real time. Our results have shown that measurements are performed accurately, both for adult and preterm neonate breathing characteristics. We have further shown, for the first time, that it is possible to measure ALWC in situ directly at the patient interface.

\section{Materials and Methods}

\section{Aerosolizer system}

An aerosolizer system was used, consisting of a continuous dry-powder aerosolizer (CPA) in combination with a humidification chamber, which additionally humidifies and heats the aerosol. ${ }^{(26)}$ This system is able to administer high concentrations of recombinant surfactant protein- $\mathrm{C}$ by a continuous aerosol flow of $0.84 \mathrm{~L} / \mathrm{min}$ and releases humidified surfactant particles with a mass median diameter in the range of $3-3.5 \mu \mathrm{m} .^{(27,28)}$

\section{Test bench for preterm neonate inhalers}

The original preterm neonate inhaler test bench has been described by Pohlmann and Helwich. ${ }^{(22)}$

In this approach, the rotary pump circulates a volume flow between the end of the patient interface and the gravimetric filter in the circuit. This results in a closed system between the end of the patient interface and the filter. Consequently, the particles cannot pass over the end of the patient interface. However, as soon as the test lung simulates an inspiration, the particles are sucked out of the patient interface and collected on the gravimetric filter. During exhalation, the remaining particles in the area of the patient interface are removed. Due to this arrangement, the device dead space no longer needs to be considered between the patient interface and the filter, but only between the beginning and the end of the patient interface. This allows an application for the breathing parameters of preterm neonates. We equipped this original test bench with additional detection units for measurement of inhaled and non-inhaled aerosol (Fig. 1), as described in the patent WO/2020-007858 A1. ${ }^{(29)}$

The test bench parameters were derived on a spontaneously breathing preterm neonate $[2000 \mathrm{~g},<38$ weeks gestational age ${ }^{(30)}$ ] under NCPAP (nasal continuous positive airway pressure) respiratory support. Preterm neonate breathing characteristics were simulated by a test lung consisting of a silicone bellow and shaft, operated by a linear motor (PS02-23Sx80F-HP-K; NTI AG LinMot \& MagSpring, Spreitenbach, Switzerland). The test lung simulated the breathing using an inhalation-exhalation ratio (I:E) of $0.39: 0.61,51$ breaths/min, and a tidal volume of $12.3 \mathrm{~mL} .^{(20,31-33)}$ The measurement cycle had a duration of about 144 seconds, resulting in a total inhalation volume of about $1.5 \mathrm{~L}$. A nasal prong was used as patient interface (Fig. 1), but a nasal mask is also feasible. ${ }^{(34)}$ The medical ventilation circuit was utilized by a Babylog ${ }^{\circledR} 8000$ plus (Drägerwerk AG \& Co. KGaA, Lübeck, Germany) and operated in CPAP (continuous positive airway pressure) mode with a positive end expiratory pressure of $5 \mathrm{mbar}$ and a 


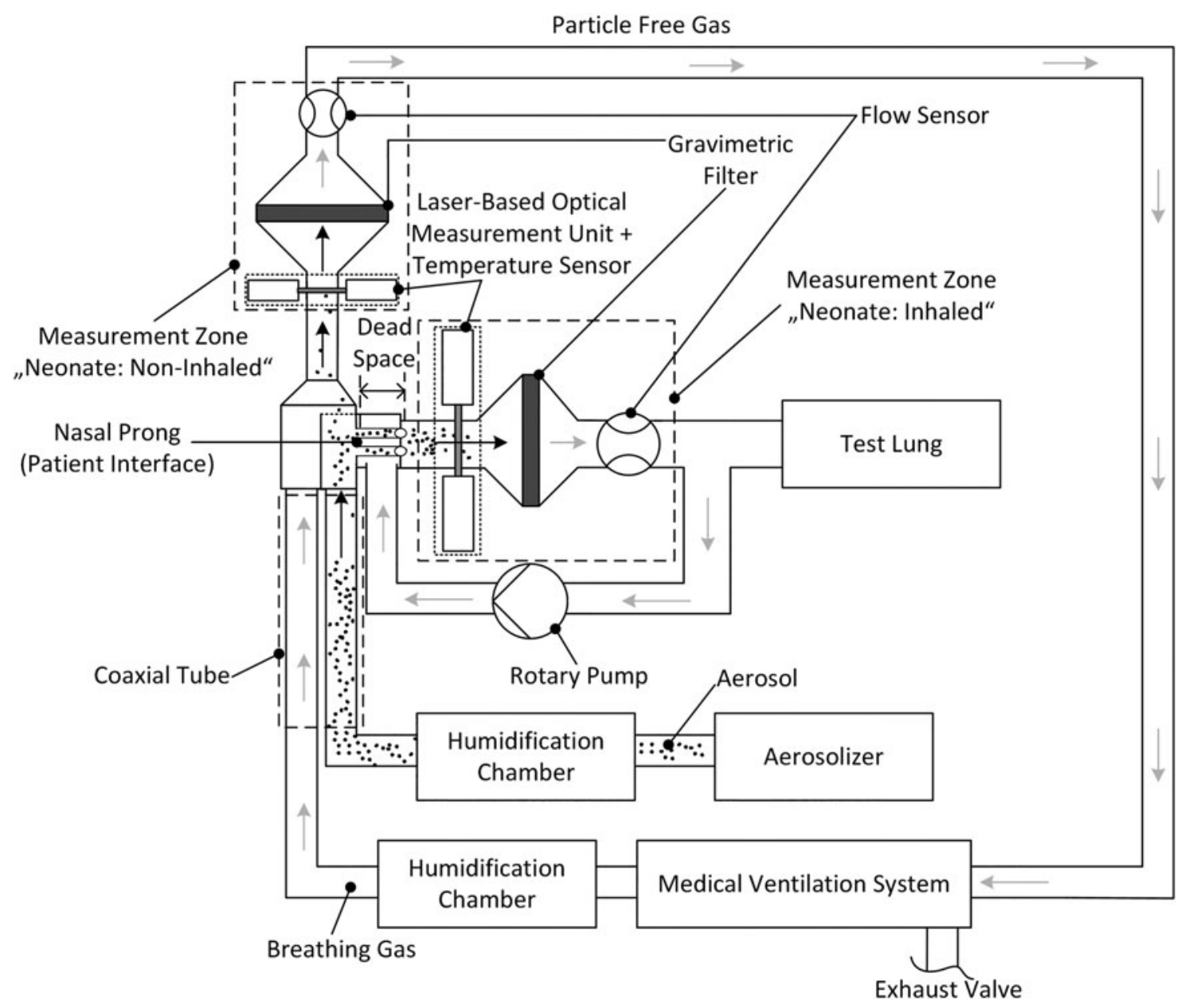

FIG. 1. Preterm neonate inhaler test bench with two integrated laser-based optical measurement units upstream of gravimetric filters, making use of simulated preterm neonate breathing characteristics. This test bench is based on ISO 27427 and two patents.

breathing gas flow of $6 \mathrm{~L} / \mathrm{min}$. Both the aerosol and breathing gas were heated $\left(45^{\circ} \mathrm{C}\right)$ and humidified $(100 \%$ r.H) in a humidification chamber. They were then conditioned in a subsequent coaxial tube, where they were cooled down to be at $36.5^{\circ} \mathrm{C}$ at the patient interface, leading to supersaturation and subsequent condensation of water onto the particles (100\% r.H). Temperatures inside the laser-based optical measurement units were measured (Temperature Transmitter Red-MU-PT100-44P; Meilhaus Electronic GmbH, Alling, Germany) to calculate local absolute humidities $H_{\text {optic }}$.

During a simulated inhalation, particles were sucked through the nasal prong into the measurement zone "neonate: inhaled" (Fig. 1). Once there, these "inhaled aerosol" particles were first measured by the laser-based optical measurement unit (light extinction), followed by particle sampling on the filter. Particles not sucked in were guided toward the measurement zone "neonate: non-inhaled" during a simulated exhalation. These "non-inhaled particles" were then measured by the second laser-based optical measurement unit (light extinction), followed by sampling of these particles on a second filter, resulting in particle-free gas that was conducted back to the medical ventilation system.

The total flows $\dot{V}(t)$ in the measurement zone "neonate: inhaled" and $\dot{V}(t)$ in the measurement zone "neonate: non- inhaled" were measured with a flow sensor (Mass Flow Meter SFM3000; Sensirion AG, Staefa ZH, Switzerland). This parameter was also used in older measurements under the same flow conditions.

\section{Test bench for common adult inhalers}

In a modified test bench for inhalers for adults, an additional laser-based optical measurement unit for light extinction measurements was integrated (Fig. 2). The adult breathing characteristics in this test bench were simulated using a sine pump (BRS 1000; Copley Scientific, Nottingham, United Kingdom) with an I:E of 1:1, $15 \mathrm{bmp}$, and a tidal volume of $500 \mathrm{~mL}$. Each measurement cycle comprised two breathing cycles with a total duration of 8 seconds. A standard mouthpiece was used as patient interface. Dry or humidified aerosol was delivered to the patient interface. Heated and humidified aerosol ${ }^{(26)}$ was delivered to the patient interface at $100 \%$ relative humidity (r.H.) and $32^{\circ} \mathrm{C}$. The temperature inside the optical measurement unit was set to the slightly higher value of $32.9^{\circ} \mathrm{C}$.

As soon as the sine pump started a simulated inhalation, the aerosol was sucked into the measurement zone "adult: inhaled." These "inhaled" particles were first detected by 


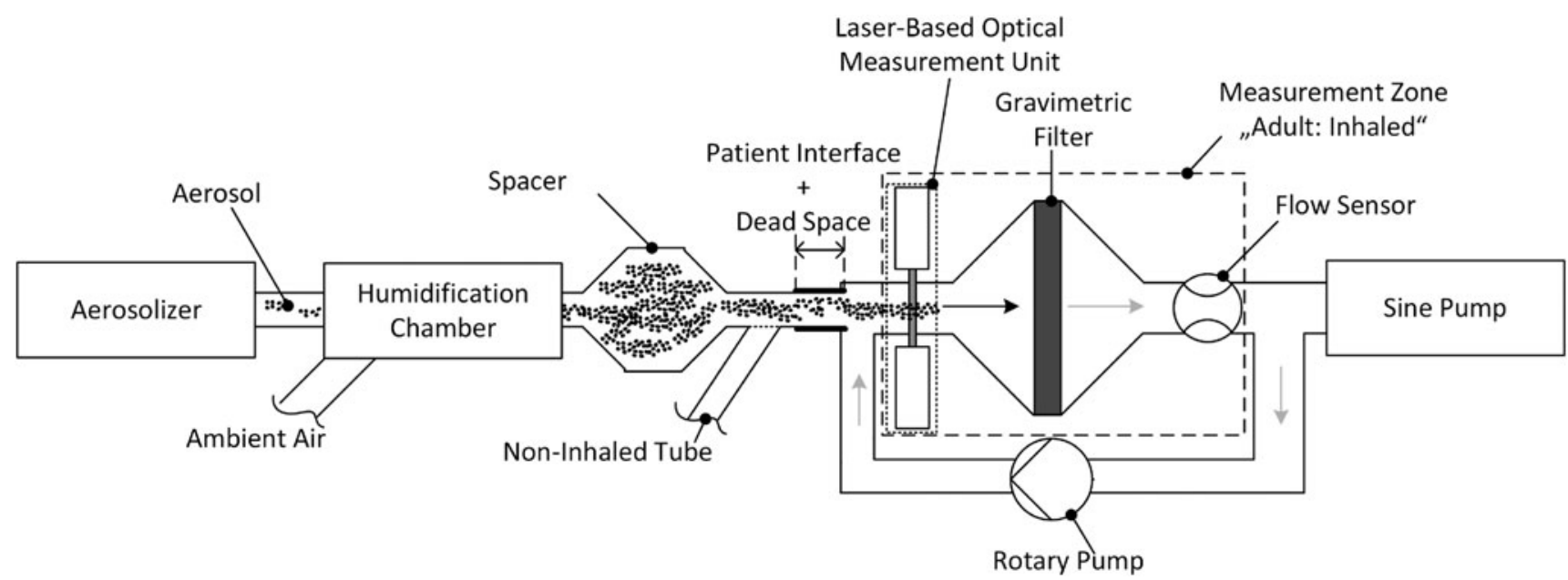

FIG. 2. Adult inhaler test bench with an integrated laser-based optical measurement unit added upstream of a gravimetric filter, simulating adult breathing characteristics. This test bench is based on ISO 27427 and two patents.

the laser-based optical measurement unit (light extinction), followed by sampling on the filter. During a simulated exhalation, the particles remaining in the patient interface were drained out of the patient interface through the "non-inhaled tube" utilizing special valves. The total flow $\dot{V}(t)$ in the measurement zone "adult: inhaled" was measured with a flow sensor (Mass Flow Meter SFM3000; Sensirion AG).

\section{Determination of dry mass}

For the determination of dry particle mass, filters (glass fibers, $80 \mathrm{~mm}$ diameter) were conditioned before and after sampling. For conditioning, the filters were first dried at a temperature of $60^{\circ} \mathrm{C}$ for 6 hours, then acclimatized for 24 hours at a constant relative humidity of $30 \%$ and weighed three times by a measuring robot developed at Fraunhofer ITEM (weighing accuracy $\pm 0.04 \mathrm{mg}$ ). The difference between initial and final weight is the mass of dried particles collected on the filter.

\section{Laser-based optical measurement units}

For optical particle measurement, we used light extinction by aerosol particles. The optical measurements were performed by a laser-based optical measurement unit. Each unit made use of an infrared diode laser system with detector (Laser Beam Sensor LA-511; Panasonic Electric Works Europe AG, Ottobrunn, Germany), facilitating a beam height of $15 \mathrm{~mm}$, a beam width of $\leq 1 \mathrm{~mm}$, and a wavelength of $780 \mathrm{~nm}$. The advantage of this geometry is its large detection cross section with a high measurement sensitivity and dynamic range. To ensure that the laser beam is not refracted as it passes through the optical windows, it enters and exits vertically (Fig. 3).

Polymethyl methacrylate was utilized for the optical window, due to its high transmittance of about $92 \%$ in the range of the laser beam wavelength of $780 \mathrm{~nm}$. The path length (L) between the transmitter and receiver was $27.5 \mathrm{~mm}$ for the adult inhaler test bench and $32 \mathrm{~mm}$ for the preterm neonate inhaler test bench.

\section{Determination of aerosol output and aerosol output rate by optical measurement}

The output $v(t)$ measured with the laser system is as follows:

$$
v(t)=e_{\mathrm{sys}} I(t),
$$

where $e_{\text {sys }}$ is a constant describing the transfer function of the optical measurement system and $I(t)$ is the light incident on the detector with light attenuation by the aerosol in the optical path at time $t$. The description of incident light following Lambert Beer's law is as follows:

$$
I(t)=I_{0} \times e^{-\sigma_{e} \times c(t) \times L},
$$

where $I_{0}$ is the light incident on the detector without aerosol, $L$ is the optical path length, $\sigma_{e}$ the (substance-dependent) extinction coefficient, and $c(t)$ the (aerosol) concentration

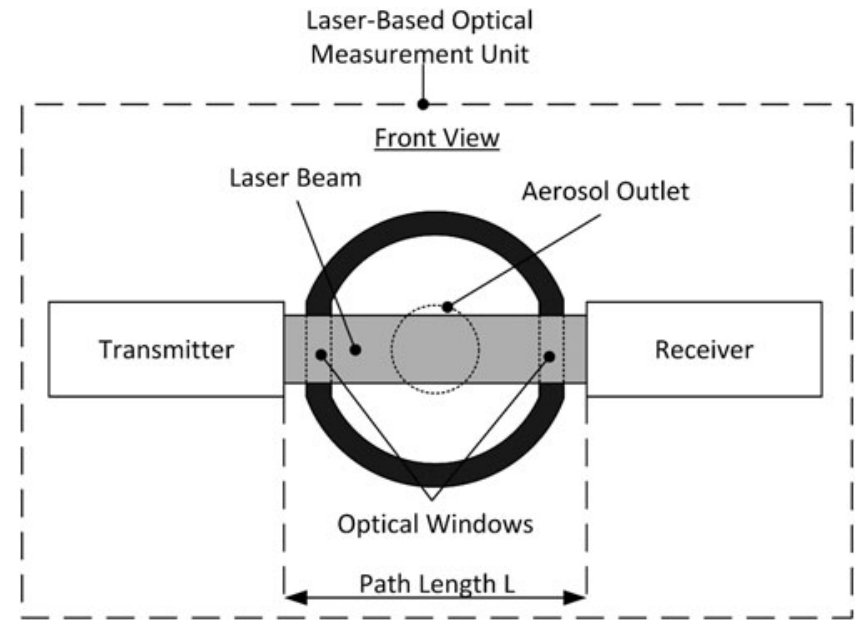

FIG. 3. Front view of the laser-based optical measurement unit. The optical windows were perpendicular to the laser beam to prevent refraction. The geometry of the laser beam allows a large detection cross section. 
averaged over the optical cross section. Combining $\sigma_{e}$ and $L$ in one constant $k$ results in the following:

$$
c(t)=\frac{-\ln \left(\frac{I(t)}{I_{0}}\right)}{k}
$$

The mass $m$ sampled on the filter downstream of the laser system during one measurement cycle depends on the aerosol concentration $c(t)$ passing through the measurement volume and the volume sucked through the filter. $V$ is the total volume of aerosol passing through the measurement zone during time $t=t_{0}$ (start of measurement cycle) to $t=t_{\text {end }}$ (end of measurement cycle). The volume $V$ depends on the total flow $\dot{V}(t)$ circulating in the corresponding measurement zone. Hence, the total mass $m_{\text {total }}$ passing through the respective measurement zone and being sampled on the filter during one measurement cycle can be expressed as follows:

$$
\begin{aligned}
m_{\text {total }} & =\int_{t_{0}}^{t_{\text {end }}} \dot{m}(t) \mathrm{d} t=\int_{t_{0}}^{t_{\text {end }}} c(t) \dot{V}(t) \mathrm{d} t \\
& =\frac{1}{k} \int_{t_{0}}^{t_{\text {end }}}-\ln \left(\frac{I(t)}{I_{0}}\right) \dot{V}(t) \mathrm{d} t,
\end{aligned}
$$

where $\ln \left(\frac{I(t)}{I_{0}}\right)$ is measured by the optical laser system and $\dot{V}(t)$ is measured by the flow sensor (Figs. 1 and 2) of the respective measurement zone.

In the case of humidified particles, the total mass $m_{\mathrm{total}}$ is the sum of dry particle mass $m_{\mathrm{dry}}$ and the amount of water $m_{\text {water }}$ condensed onto the particles:

$$
m_{\mathrm{total}}=m_{\mathrm{dry}}+m_{\mathrm{water}} .
$$

Assuming that the constant $k$ is approximately independent of particle composition, it follows:

$$
\begin{aligned}
m_{\text {total }} & =m_{\text {dry }}+m_{\text {water }} \\
& =\int_{t_{0}}^{t_{\text {end }}}\left(\dot{m}_{\text {dry }}(t)+\dot{m}_{\text {water }}(t)\right) \mathrm{d} t \cong \frac{1}{k} \int_{t_{0}}^{t_{\text {end }}}-\ln \left(\frac{I(t)}{I_{0}}\right) \dot{V}(t) \mathrm{d} t .
\end{aligned}
$$

Hence:

$$
m_{\mathrm{dry}} \cong \frac{1}{k} \times \int_{t_{0}}^{t_{\mathrm{end}}}-\ln \left(\frac{I(t)}{I_{0}}\right) \dot{V}(t) \mathrm{d} t-m_{\mathrm{water}} .
$$

Since the extinction coefficient $\sigma_{e}$ of the measured aerosol is not known, the constant $k$ cannot be determined $a b$ initio. However, assuming that the aforementioned conditions (optical, physical, and chemical properties) do not change during the measurements, simple linear regression between the gravimetrically weighed dry mass $m_{\text {dry }}$ and $\int_{t_{0}}^{t_{\text {end }}}-\ln \left(\frac{I(t)}{I_{0}}\right) \dot{V}(t) \mathrm{d} t$ allows determination of the constant $k$ and the amount of water $m_{\text {water: }}$ :

$$
m_{\mathrm{dry}}=\beta_{1} \times \int_{t_{0}}^{t_{\text {end }}}-\ln \left(\frac{I(t)}{I_{0}}\right) \dot{V}(t) \mathrm{d} t+\beta_{0},
$$

where the regression coefficient $\beta_{1}$ represents the $1 / k$ factor and the regression coefficient $\beta_{0}$ the water mass $m_{\text {water. }}$ As $I_{0}$ in the real system decreases over time, caused by aerosol deposition and water condensation onto the optical windows, we calculated $I_{0}(t)$ by simple linear regression over the first and last three measurement points of $I_{0}$ and the corresponding time $\mathrm{t}$ as follows:

$$
I_{0}(t)=\beta_{1} \times t+\beta_{0}
$$

\section{Plausibility check for ALWC}

The water condensing onto the particles originates from water vapor through cooling and can be determined by the difference in saturation at different temperatures. Neglecting vapor pressure reduction due to dissolved solutes, the saturation humidity $H$ at temperature $T$ can be expressed as follows:

$$
H=\left(\frac{e_{\mathrm{sat}}}{R_{w} \times T}\right),
$$

where $e_{\text {sat }}$ is the saturation vapor pressure calculated by the August-Roche-Magnus equation and $R_{w}$ the specific gas constant of water. The amount of water in the gas phase $H_{\text {available }}$ that can condense onto the particles can be estimated from the difference in absolute humidities between patient interface $H_{\text {interface }}$ and optical measurement unit $H_{\text {optic }}$ at saturation humidity:

$$
H_{\text {available }}=H_{\text {interface }}-H_{\text {optic }} \text {. }
$$

The absolute humidity at the patient interface $H_{\text {interface }}$ is calculated by the following:

$$
H_{\text {interface }}=\left(\frac{H_{\text {aerosol }} \times \dot{V}_{\text {aerosol }}+H_{\text {breathing gas }} \times \dot{V}_{\text {breathing gas }}}{\dot{V}_{\text {aerosol }}+\dot{V}_{\text {breathing gas }}}\right),
$$

using the flow of the aerosolizer $\dot{V}_{\text {aerosol, }}$, the flow of the breathing gas $\dot{V}_{\text {breathing gas, the absolute humidity of the }}$ aerosol $H_{\text {aerosol }}$, and the absolute humidity of the breathing gas $H_{\text {breathing gas. }}$ Based on the aforementioned conditions, we estimated an absolute humidity at the patient interface of $H_{\text {interface, adult }}=36 \frac{\mathrm{mg}}{\mathrm{L}}$ for the adult inhaler test bench and of $H_{\text {interface, neonate }}=45.46 \frac{\mathrm{mg}}{\mathrm{L}}$ for preterm neonates.

\section{Results and Discussion}

\section{Optical measurements}

Figure $4 \mathrm{a}$ and $\mathrm{b}$ provides the light incident $I(t)$ on the detector after passing through the measurement zone "adult: inhaled" for (a) dry aerosol and (b) humidified aerosol during one inhalation cycle of 2 seconds. Figure $4 \mathrm{c}$ and $\mathrm{d}$ shows the light incident $I(t)$ on the detector after passing through the measurement zones (c) "neonate: inhaled" and (d) "neonate: non-inhaled" for humidified aerosol over several breaths within a period of 140 seconds each.

The graphs for (a) dry aerosol and (b) humidified aerosol in the measurement zone "adult: inhaled" show close matches (same particle mass of $\approx 1 \mathrm{mg}$ was sampled in both cases on the filters). However, the light incident $I(t)$ on the 

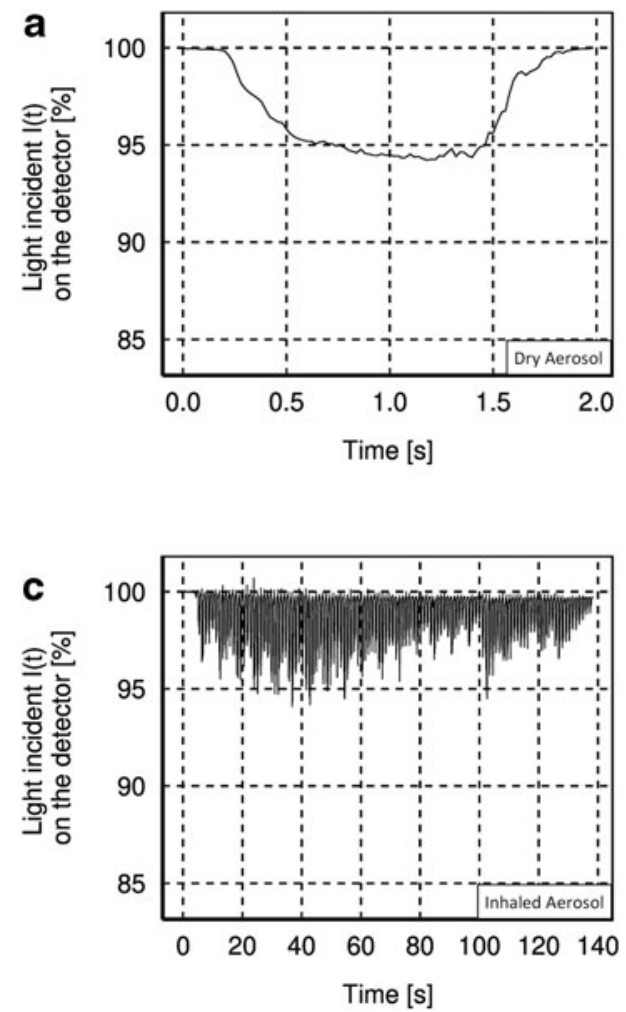
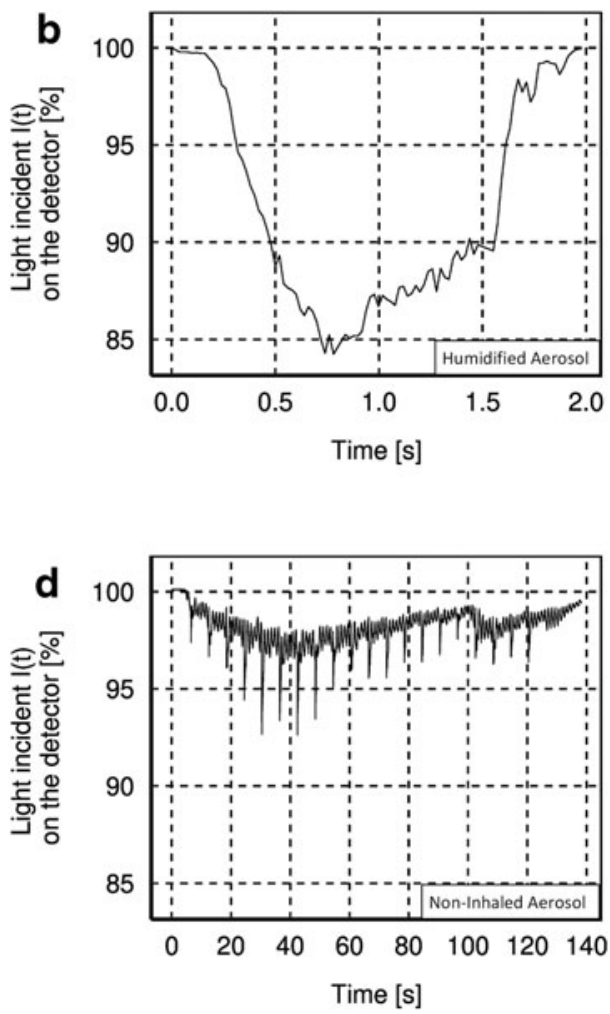

FIG. 4. Diagrams of the light incident $I(t)$ on the detector in (\%) over time in (second) in the measurement zone "adult: inhaled" for (a) dry aerosol and (b) humidified aerosol, and in the measurement zones (c) "neonate: inhaled" and (d) "neonate: non-inhaled" for humidified aerosol.

detector is less for humidified aerosol than for dry aerosol. The light incident $I(t)$ on the detector in the measurement zone "neonate: inhaled" (Fig. 4c) varies between particle detection $(I(t)<100 \%)$ and no particle detection $(I(t)=100 \%)$, with partly false peak overshoots $(I(t)>100 \%)$, whereas in the measurement zone "neonate: non-inhaled" (Fig. 4d), a signal $I(t)<100 \%$ was detected during the whole measurement period. Furthermore, both figures simultaneously exhibit periodic narrow-bands of signal attenuation due to the operating principle of the CPA with its short 10 mseconds pulses of pressurized gas every 6 seconds, ${ }^{(28)}$ which appear more prominent but with less background in the measurement zone "neonate: non-inhaled." It is also obvious that $I_{0}$ (baseline) decreases over time, as noted previously.

\section{Correlation between optical and gravimetric measurements}

The correlation of optical measurements with gravimetrically determined dry mass is shown in Figure 5a for dry $(n=13)$ and humidified aerosol $(n=53)$ for the measurement
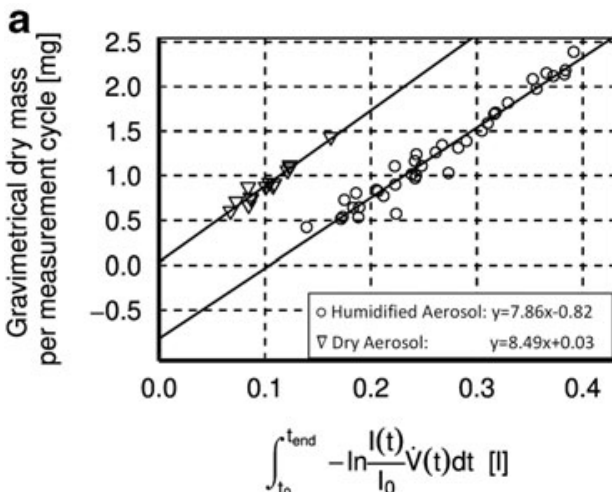

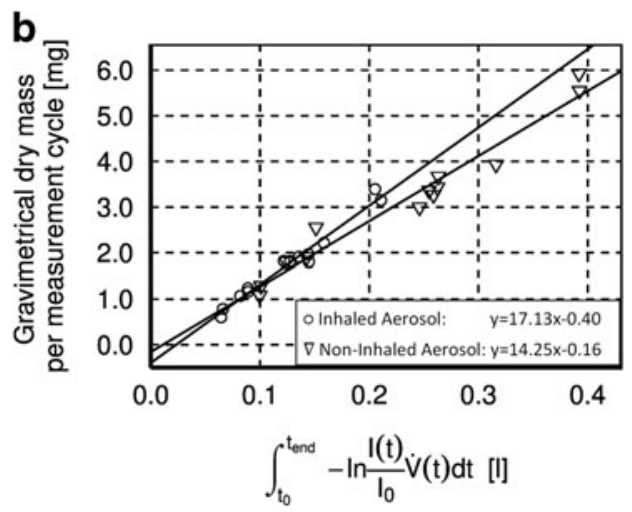

FIG. 5. Diagrams showing the correlation of optical and gravimetric measurements (points $=$ single-measurement cycle) of $(\mathbf{a})$ dry $(\mathrm{R} 2=0.94)$ and humidified $(\mathrm{R} 2=0.96)$ aerosol using the adult inhaler test bench, and $(\mathbf{b})$ inhaled $(\mathrm{R} 2=0.97)$ and non-inhaled $(\mathrm{R} 2=0.96)$ humidified aerosol using the preterm neonate inhaler test bench. 
Table 1. Temperature Measured Inside the Laser-Based Optical Measurement Units and Theoretically Estimated Amount of Water Available for Condensation onto Particles

\begin{tabular}{|c|c|c|c|c|}
\hline $\begin{array}{l}\text { Measurement } \\
\text { zone }\end{array}$ & Aerosol & $\begin{array}{c}\text { Temperature inside } \\
\text { the laser-based } \\
\text { optical measurement } \\
\text { unit }\left({ }^{\circ} \mathrm{C}\right)\end{array}$ & $\begin{array}{c}\text { Theoretically estimated } \\
\text { amount of water } \\
\text { available for condensation } \\
\text { per liter volume }(\mathrm{mg} / \mathrm{L})\end{array}$ & $\begin{array}{l}\text { Theoretically estimated } \\
\text { amount of water available } \\
\text { for condensation per } \\
\text { measurement cycle ( } \mathrm{mg})\end{array}$ \\
\hline \multirow[t]{2}{*}{ Adult: inhaled } & Dry & 一 & 0 & 0 \\
\hline & Humidified & 32.9 & 0.7 & 0.7 \\
\hline Neonate: inhaled & Humidified & 35.61 & 0.94 & 1.4 \\
\hline Neonate: non-inhaled & Humidified & 41.19 & 0 & 0 \\
\hline
\end{tabular}

zone "adult: inhaled." Figure 5b shows the corresponding correlation for humidified aerosol in the measurement zones "neonate: inhaled" $(n=13)$ and "neonate: non-inhaled" $(n=13)$.

\section{Humidification of dry-powder aerosol in humidifier systems of aerosol generators: estimation of potential amount of water available for condensation onto dry particles}

Condensation was optically observed in all laser-based optical measurement units when using humidified aerosol, thus indicating a relative humidity of the air surrounding the particles in the measuring volume $\geq 100 \%$. The measured average temperature $T$ inside the laser-based optical measurement unit (Fig. 3), as well as the amount of water available for condensation onto particles per liter volume and per measurement cycle, estimated according to Equation (11), is listed in Table 1. To determine the amount of water available for condensation onto particles per measurement cycle, the corresponding aerosol volume passing through the measurement zone was taken into account.

We combined optical with gravimetric detection to enable real-time measurement of aerosol output. Our results show a high correlation between gravimetric and optical detection of more than $R^{2}>0.94$ (Fig. 5), for both dry and humidified aerosol. This high correlation is consistent with data obtained in previous studies. ${ }^{(23-25)}$ Nevertheless, when using humidified aerosol, we observed that the regression line did not pass through the origin but had a negative offset on the gravimetric axis. The observed offset results from comparison of the optical signal caused by humidified aerosol with the dry particle mass on the filter. Light extinction of the humidified, still airborne particles exhibits a stronger signal than expected for dry particles. We hypothesize that the difference is due to additional water on the particles, thus leading to an enlarged scattering cross section. Since we also observed a linear relationship between light extinction by humidified aerosol and dry particle mass, we further hypothesize that the offset found is a measure of water uptake by particles in the airborne state. This is in line with the findings reported by Wallace et al., ${ }^{(35)}$ demonstrating a high bias in optical detection of humidified particles compared to measurement of dry weight with filter-based instruments.

To confirm these assumptions, measurements with the adult inhaler test bench were carried out with dry and humidified aerosol. The dry measurements confirmed the linear relationship between optical signal and sampled aerosol with an offset of almost zero. The offset observed for humidified particles therefore is clearly related to water uptake by particles. It is known that the particle cross section increases $^{(36-39)}$ with water content, depending on the hygroscopicity, and thus, a larger optical signal is measured due to increased light extinction. On the contrary, simple condensation of water onto the particle surface would also lead to particle growth. This is also consistent with the measurement result showing that the light attenuation of humidified aerosol is about $8 \%$ stronger than attenuation of a comparable dry aerosol.

Accordingly, it is obvious that under certain temperature and humidity conditions, the gravimetric offsets for humidified aerosol are measures of water uptake by the aerosol (Fig. 6).

Hence, the extrapolated ALWC (gravimetric offset) corresponds very well to the estimated amount of water per measurement cycle (Table 2).

As expected, the difference between the estimated and measured ALWC is negligible for the measurement zone "adult: inhaled" when using dry aerosol. Using humidified aerosol, the deviation observed can be explained, for example, by competing water condensation onto the aerosolconducting tubes.

For the measurement zone "neonate: inhaled," the discrepancy found is larger. This is due to the fact that the temperature of the aerosol in the inhaler system on purpose is always higher than the surrounding tube walls and this was not taken into account in the simple estimation we performed. Since the aerosol is reheated above the dew point in the measurement zone "neonate: non-inhaled," partial water evaporation occurs, and this is also in concurrence with evaporation kinetics. We calculated (one-way coupled) ${ }^{(40)}$

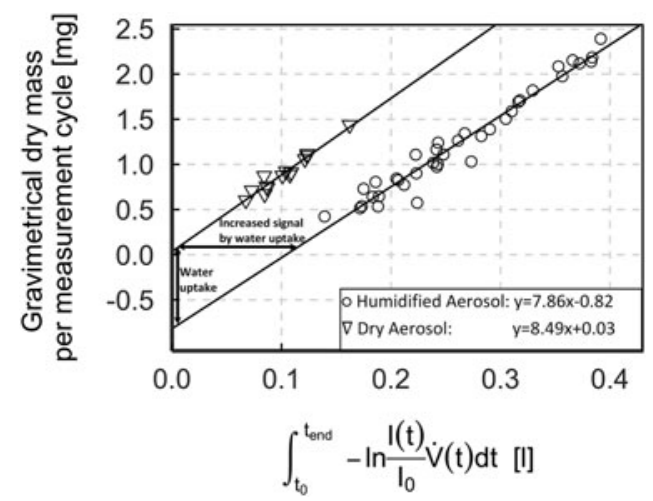

FIG. 6. Representation of water uptake by the aerosol and its increased signal. 
Table 2. Tabulated Summary of Estimated and Extrapolated Aerosol Liquid Water Contents and Their Difference, TaKen from Figure 5 and Table 1

\begin{tabular}{lcccc}
\hline Measurement zone & Aerosol & $\begin{array}{c}\text { Theoretically estimated } \\
\text { ALWC per measurement } \\
\text { cycle }(\mathrm{mg})\end{array}$ & $\begin{array}{c}\text { ALWC extrapolated } \\
\text { from measurement data } \\
\text { per measurement cycle }(m g)\end{array}$ & $\begin{array}{c}\text { Difference between } \\
\text { estimated and } \\
\text { extrapolated ALWC }(m g)\end{array}$ \\
\hline Adult: inhaled & Dry & 0 & $\approx 0$ & $\approx 0$ \\
Neonate: inhaled & Humidified & 0.7 & 0.82 & 0.12 \\
Neonate: non-inhaled & Humidified & 1.4 & 0.4 & -1 \\
\hline
\end{tabular}

ALWC, aerosol liquid water content.

that total evaporation of the aerosol in the measurement zone "neonate: non-inhaled" would take 5.8 mseconds. However, the residence time of the aerosol in the measurement zone "neonate: non-inhaled" is only about 3.2 mseconds. Since the droplet lifetime, estimated with oneway coupled analysis, is greater than the total evaporation time of the aerosol, a two-way coupled hygroscopic estimation would give even smaller size changes. Thus, twoway coupled hygroscopic effects can be neglected, and the first estimation is safe to use. ${ }^{(41)}$

The approach to extrapolate the ALWC from the correlation between optical signal and dry mass on the filter is based on the assumption that the extinction coefficient $\left(\sigma_{e}\right)$ does not considerably change with variating aerosol layer composition. Applying the algorithm of Bohren and Huffman for coated spheres, ${ }^{42)}$ we calculated the extinction coefficient for six different scenarios (Table 3).

The extinction coefficients of $3 \mu \mathrm{m}$ dry surfactant particles, containing a $0.25 \mu \mathrm{m}$ liquid layer of water (scenario 2), of $10 \% \mathrm{NaCl}$ (scenario 3), and of $30 \% \mathrm{NaCl}$ (scenario 4), differ by $3.0 \%-6.7 \%$ compared with the pure dry surfactant particle (scenario 1). Even when using a nebulizer, which concentrates the aerosol from $10 \% \mathrm{NaCl}$ (scenario 5) to $30 \%$ $\mathrm{NaCl}$ (scenario 6) over time, the calculated extinction coefficient changes by only $5.7 \%$. As the extinction coefficient $\sigma_{e}$ does not change considerably with varying compositions of the aerosol layer and the aforementioned differences are small compared with the variations observed during practical measurements (Fig. 6), a correlation between optical signal and dry mass on the filter is feasible.

To verify that the observed ALWC is in accordance with changes in measured particle size, we assumed that the condensed water is used mainly to build up a layer on the surface of the dry surfactant powder and is absorbed by the powder only to a small amount. Particle size calculations are based, on the one hand, on the ALWC measured with the adult inhaler test bench and, on the other hand, on size distributions of the aerosol emitted at the patient interface of the adult systems.

The measured particle size distribution of the dry surfactant at the patient interface has an MMAD of $3.16 \mu \mathrm{m}$ and a GSD of 2.1. (28) Based on these values, the rough change in particle size by humidification is estimated for the adult inhaler test bench assuming a water layer of identical thickness condensing onto all particles. Taking into account the water condensing onto the particles, a water layer of $0.31 \mu \mathrm{m}$ is obtained for the measured ALWC of $0.82 \mathrm{mg}$ per measurement cycle using the adult inhaler test bench. This results in an MMAD of $3.79 \mu \mathrm{m}$ and a GSD of 1.91 for the recalculated humidified surfactant, which is in good agreement with the values measured for the humidified surfactant (MMAD of $3.6 \mu \mathrm{m}$ and GSD of 1.8 , nonpublished verification results). This also supports the hypothesis that the amount of water condensed on the particles is predictable using the above system.

However, it must be taken into account that with complex formulations, such as semivolatile organic compounds, mass determination by filter weighing can lead to errors due to volatilization after sampling on the filter (also known as negative artifact). ${ }^{(45-48)}$ In such cases, chemical mass analysis is preferable to simple filter weighing.

Nevertheless, the presented novel test stand is unique as it is able to determine the aerosol output in real time and the water content of the aerosol directly at the patient interface as well as being easily adopted and used in other laboratories.

Table 3. Calculation of Extinction Coefficients for Different Aerosol Compositions

\begin{tabular}{|c|c|c|c|}
\hline Scenario & Aerosol composition & Refractive index $\mathrm{n}$ & $\begin{array}{l}\text { Extinction } \\
\text { coefficient }\end{array}$ \\
\hline 1 & $\begin{array}{l}\text { Dry surfactant sphere with } 3 \mu \mathrm{m} \\
\text { diameter }\end{array}$ & $1.590+0.66 \mathrm{i}^{(40)}$ & 2.343 \\
\hline \multirow[t]{2}{*}{2} & $\begin{array}{l}\text { Dry surfactant sphere with } 3 \mu \mathrm{m} \\
\text { diameter }\end{array}$ & $1.590+0.66 \mathrm{i}^{(40)}$ & 2.414 \\
\hline & Water layer of $0.25 \mu \mathrm{m}$ & $1.321+1.27 \mathrm{E}-07 \mathrm{i}$, calculated according to $\mathrm{Li}$ et al. ${ }^{(43,44)}$ & \\
\hline \multirow[t]{2}{*}{3} & $\begin{array}{l}\text { Dry surfactant sphere with } 3 \mu \mathrm{m} \\
\text { diameter }\end{array}$ & $1.590+0.66 \mathrm{i}^{(40)}$ & 2.455 \\
\hline & $10 \% \mathrm{NaCl}$ layer of $0.25 \mu \mathrm{m}$ & $1.340+1.32 \mathrm{E}-07 \mathrm{i}$, calculated according to $\mathrm{Li}$ et al. ${ }^{(43,44)}$ & \\
\hline \multirow[t]{2}{*}{4} & $\begin{array}{l}\text { Dry surfactant sphere with } 3 \mu \mathrm{m} \\
\text { diameter }\end{array}$ & $1.590+0.66 \mathrm{i}^{(40)}$ & 2.500 \\
\hline & $30 \% \mathrm{NaCl}$ layer of $0.25 \mu \mathrm{m}$ & $1.368+1.42 \mathrm{E}-07 \mathrm{i}$, calculated according to $\mathrm{Li}$ et al. ${ }^{(43,44)}$ & \\
\hline 5 & $3.5 \mu \mathrm{m}$ Sphere of $10 \% \mathrm{NaCl}$ & $1.340+1.32 \mathrm{E}-07 \mathrm{i}$, calculated according to $\mathrm{Li}$ et al. ${ }^{(43,44)}$ & 2.578 \\
\hline 6 & $3.5 \mu \mathrm{m}$ Sphere of $30 \% \mathrm{NaCl}$ & $1.368+1.42 \mathrm{E}-07 \mathrm{i}$, calculated according to $\mathrm{Li}$ et al. ${ }^{(43,44)}$ & 2.747 \\
\hline
\end{tabular}




\section{Conclusion}

We have shown that optical and gravimetric measurements are highly correlated when comparing dried and humidified aerosol, using breathing characteristics of both adults and preterm neonates. As the effort for gravimetric measurements is reduced to ideally two measurements (low and high concentrations) and further results can be gathered in real time, the system allows a much faster, quantitative measurement of aerosol output and aerosol output rate. In contrast to chemical water content analysis, for example, our test bench does not alter the aerosol and, for the first time, enables measurement of the ALWC in situ directly at the patient interface. Therefore, the test bench can be used for the development and rapid optimization of new inhalers. In particular, it can be used for the development and optimization of a breath-triggered aerosol release system for preterm neonates. Due to its applicability in test benches based on ISO 27427, this new approach has the potential to be used in various sectors.

\section{Disclaimer}

The content is the sole responsibility of the authors and does not necessarily reflect the views of the aforementioned parties.

\section{Author Disclosure Statement}

The authors declare they have no competing financial interests.

\section{Funding Information}

This work has been supported by funding from the European Union (EU) within its Horizon 2020 programme, project MDOT (Medical Device Obligations Taskforce), Grant agreement 814654, and from the German Federal Ministry of Education and Research (BMBF), Grant agreement GS2SH016.

\section{References}

1. Smaldone GC, Walser L, Perry RJ, Ilowite JS, Bennett WD, and Greco M: Generation and administration of aerosols for medical and physiological research studies. J Aeros Med. 1989;2:81-87.

2. Smaldone GC: Drug delivery via aerosol systems: Concept of "aerosol inhaled". J Aeros Med. 1991;4:229-235.

3. Dennis JH: Drug nebuliser design and performance: Breath enhanced jet vs. constant output jet vs. ultrasonic. J Aeros Med. 1995;8:277-280.

4. Smaldone GC, Cruz-Rivera M, and Nikander K: In vitro determination of inhaled mass and particle distribution for budesonide nebulizing suspension. J Aeros Med. 1998;11: 113-125.

5. O'Riordan TG, Weinstein MD, and Mao Y: Bench testing of nebulizers: A comparison of three methods. J Aeros Med. 1999;12:59-66.

6. Nikander K, Denyer J, Everard M, and Smaldone GC: Validation of a new breathing simulator generating and measuring inhaled aerosol with adult breathing patterns. J Aeros Med. 2000;13:139-146.

7. Nikander K, Turpeinen M, and Wollmer P: Evaluation of pulsed and breath-synchronized nebulization of budesonide as a means of reducing nebulizer wastage of drug. Pediatr Pulmonol. 2000;29:120-126.

8. Ge H-Q, Wang J-M, Lin H-L, Fink JB, Luo R, Xu P, and Ying $\mathrm{K}$ : Effect of nebulizer location and spontaneous breathing on aerosol delivery during airway pressure release ventilation in bench testing. J Aeros Med Pulmon Drug Deliv. 2019;32:34-39.

9. International Organization for Standardization: Anaesthetic and Respiratory Equipment-Nebulizing Systems and Components Components (ISO 27427:2013); 11.040.10 Anaesthetic, Respiratory and Reanimation Equipment, 2013. Geneva, Switzerland.

10. Dunber CA, Hickey AJ, and Holzner P: Dispersion and characterization of pharmaceutical dry powder aerosols. KONA. 1998;16:7-45.

11. Randriamiarisoa H, Chazette P, Couvert P, Sanak J, and Mégie G: Relative humidity impact on aerosol parameters in a Paris suburban area. Atmos Chem Phys. 2006;6:13891407.

12. Tao JC, Zhao CS, Ma N, and Liu PF: The impact of aerosol hygroscopic growth on the single-scattering albedo and its application on the $\mathrm{NO}_{2}$ photolysis rate coefficient. Atmos Chem Phys. 2014;14:12055-12067.

13. Bian YX, Zhao CS, Ma N, Chen J, and Xu WY: A study of aerosol liquid water content based on hygroscopicity measurements at high relative humidity in the North China Plain. Atmos Chem Phys. 2014;14:6417-6426.

14. Kuang Y, Zhao CS, Zhao G, Tao JC, Xu W, Ma N, and Bian YX: A novel method for calculating ambient aerosol liquid water content based on measurements of a humidified nephelometer system. Atmos Meas Tech. 2018;11: 2967-2982.

15. Finlay WH, Stapleton KW, Chan HK, Zuberbuhler P, and Gonda I: Regional deposition of inhaled hygroscopic aerosols: In vivo SPECT compared with mathematical modeling. J Biomed Opt. 1996;81:374-383.

16. Persons DD, Hess GD, Muller WJ, and Scherer PW: Airway deposition of hygroscopic heterodispersed aerosols: Results of a computer calculation. J Biomed Opt. 1987;63: 1195-1204.

17. Ferron GA, Kreyling WG, and Haider B: Inhalation of salt aerosol particles-II. Growth and deposition in the human respiratory tract. J Aeros Sci. 1988;19:611-631.

18. Finlay WH: The Mechanics of Inhaled Pharmaceutical Aerosols: An Introduction. Academic Press, San Diego, CA, 2001.

19. Fink JB: Aerosol delivery to ventilated infant and pediatric patients. Respir Care. 2004;49:653-665.

20. Walsh BK, Czervinske MP, and DiBlasi RM (eds): Perinatal and Pediatric Respiratory Care. Saunders/Elsevier, St. Louis, MO, 2010.

21. Wiegandt FC, Koch E, Iwatschenko P, Dietzel A, and Pohlmann G: Pre-triggered dry and liquid aerosol release inside the patient interface of preterm neonates. In: Journal of aerosol medicine and pulmonary drug delivery, (ed). Abstracts: International Society for Aerosols in Medicine e.V. 21st ISAM Congress Santa Fe, NM; p. A28, June 3-7, 2017.

22. Pohlmann $G$ and Helwich $O$ (Inventors): FraunhoferGesellschaft zur Förderung der angewandten Forschung e.V.: Device for determining aerosol delivery and/or aerosol delivery rate of aerosol generator device, has fluid connection point which is arranged so that the aerosol stream is partially controlled from the gas stream in filter. DE 102013103152 B3. March 27, 2013. 
23. Charlson RJ, Ahlquist NC, Selvidge H, and MacCready PB: Monitoring of atmospheric aerosol parameters with the integrating nephelometer. J Air Pollut Control Assoc. 1969; 19:937-942.

24. Kretzschmar JG: Comparison between three different methods for the estimation of the total suspended matter in urban air. Atmos Environ. 1975;9:931-934.

25. Waggoner AP and Weiss RE: Comparison of fine particle mass concentration and light scattering extinction in ambient aerosol. Atmos Environ. 1980;14:623-626.

26. Iwatschenko P and Pohlmann G (Inventors): FraunhoferGesellschaft zur Förderung der angewandten Forschung e.V. (The Fraunhofer Society for the Advancement of Applied Research): Humidifier for humidifying an aerosol. WO/2015/132172 A1. March 2, 2015.

27. Iwatschenko P, Pohlmann G, Windt H, Koch W, and Kist $\mathrm{M}$ (Inventors): Nycomed GmbH: Improved apparatus for the aerosolization of large volumes of dry powder. WO/2010/122103 A1. April 22, 2010.

28. Pohlmann G, Iwatschenko P, Koch W, Windt H, Rast M, Abreu MG de, Taut FJH, and de Muynck C: A novel continuous powder aerosolizer (CPA) for inhalative administration of highly concentrated recombinant surfactant protein-C (rSP-C) surfactant to preterm neonates. J Aeros Med Pulmon Drug Deliv. 2013;26:370-379.

29. Wiegandt FC and Pohlmann G (Inventors): FraunhoferGesellschaft zur Förderung der angewandten Forschung e.V.: Device and method for determining an aerosol delivery. WO/2020/007858 A1. July 2, 2019.

30. World Health Organization: Paediatric Age Categories to be Used in Differentiating Between Listing on a Model Essential Medicines List for Children. World Health Organization. Geneva, Switzerland, 2007.

31. Schmalisch G, Wilitzki S, and Wauer R: Differences in tidal breathing between infants with chronic lung diseases and healthy controls. BMC Pediatr. 2005;5:36.

32. te Pas AB, Davis PG, Kamlin COF, Dawson J, O'Donnell $\mathrm{CPF}$, and Morley CJ: Spontaneous breathing patterns of very preterm infants treated with continuous positive airway pressure at birth. Pediatr Res. 2008;64:281-285.

33. te Pas AB, Wong C, Kamlin COF, Dawson JA, Morley CJ, and Davis PG: Breathing patterns in preterm and term infants immediately after birth. Pediatr Res. 2009;65:352356.

34. Pinto VL and Sharma S: Continuous Positive Airway Pressure $(C P A P)$. StatPearls Publishing. Treasure Island, FL, 2020.

35. Wallace LA, Wheeler AJ, Kearney J, van Ryswyk K, You H, Kulka RH, Rasmussen PE, Brook JR, and Xu X: Validation of continuous particle monitors for personal, indoor, and outdoor exposures. J Expo Sci Environ Epidemiol. 2011;21:49-64.

36. Davis SS and Bubb MD: Physico-chemical studies on aerosol solutions for drug delivery III. The effect of relative humidity on the particle size of inhalation aerosols. Int $\mathbf{J}$ Pharm. 1978;1:303-314.
37. McMurry PH and Stolzenburg MR: On the sensitivity of particle size to relative humidity for Los Angeles aerosols. Atmos Environ. 1989;23:497-507.

38. Löndahl J, Massling A, Pagels J, Swietlicki E, Vaclavik E, and Loft S: Size-resolved respiratory-tract deposition of fine and ultrafine hydrophobic and hygroscopic aerosol particles during rest and exercise. Inhal Toxicol. 2007;19:109-116.

39. Löndahl J, Pagels J, Boman C, Swietlicki E, Massling A, Rissler J, Blomberg A, Bohgard M, and Sandström T: Deposition of biomass combustion aerosol particles in the human respiratory tract. Inhal Toxicol. 2008;20:923-933.

40. Hinds WC: Aerosol Technology: Properties, Behavior, and Measurement of Airborne Particles. Wiley, New York, 1999.

41. Finlay WH: The Mechanics of Inhaled Pharmaceutical Aerosols: An Introduction. Academic Press, London, 2019.

42. Bohren CF and Huffman DR: Absorption and Scattering of Light by Small Particles. Wiley-VCH, Weinheim, 2004.

43. Li X, Liu L, Zhao J, and Tan J: Optical properties of sodium chloride solution within the spectral range from 300 to $2500 \mathrm{~nm}$ at room temperature. Appl Spectrosc. 2015;69:635-640.

44. Li X, Liu L, Zhao J, and Tan J: Corrigendum: optical properties of sodium chloride solution within the spectral range from 300 to $2500 \mathrm{~nm}$ at room temperature. Appl Spectrosc. 2018;72:1277.

45. Baron PA and Willeke K (eds): Aerosol Measurement: Principles, Techniques, and Applications. Wiley-Interscience, New York, NY, 2001.

46. Tang H, Lewis EA, Eatough DJ, Burton RM, and Farber RJ: Determination of the particle size distribution and chemical composition of semi-volatile organic compounds in atmospheric fine particles with a diffusion denuder sampling system. Atmos Environ. 1994;28:939-947.

47. Turpin BJ, Huntzicker JJ, and Hering SV: Investigation of organic aerosol sampling artifacts in the los angeles basin. Atmos Environ. 1994;28:3061-3071.

48. Stein SW and Myrdal PB: A theoretical and experimental analysis of formulation and device parameters affecting solution MDI size distributions. J Pharm Sci. 2004;93:2158-2175.

Received on April 24, 2020

in final form, June 4, 2020

Reviewed by:

John Dennis

Warren Finlay

Address correspondence to: Felix C. Wiegandt, MSc Fraunhofer Institute for Toxicology and Experimental Medicine ITEM

Nikolai-Fuchs-Str. 1 30625 Hannover Germany

E-mail: felix.wiegandt@item.fraunhofer.de 